\title{
A implementação dos ciclos de formação em Porto Alegre: para além de uma discussão do espaço-tempo escolar
}

\author{
Andréa Rosana Fetzner \\ Universidade do Estado do Rio de Janeiro, Faculdade de Educação da Baixada Fluminense
}

O artigo apresenta parte de um estudo realizado com o apoio do Conselho Nacional de Desenvolvimento Científico e Tecnológico (CNPq) entre os anos de 2003 e $2007^{1}$ e traz uma reflexão sobre as especificidades observadas no processo de implementação dos ciclos na rede municipal de ensino de Porto Alegre. Para desenvolvimento do trabalho, proponho situar as relações entre sociedade e cultura escolar; apresentar a gênese do conceito de ciclos, em suas referências nos estudos de Vygotsky e Wallon; retomar algumas propostas educacionais desenvolvidas no Brasil que podem ser consideradas alternativas de superação dos modelos hegemônicos, como a Escola Primária Integral e a educação popular, em suas interfaces com os ciclos; e trazer a realidade específica de Porto Alegre em relação a outras propostas contemporâneas de ciclos.

\footnotetext{
${ }^{1}$ Tese de doutorado sobre as Falas docentes sobre a não-
} aprendizagem escolar em ciclos, na qual foram estudadas três redes de ensino no país que trabalham com ciclos mas que partilham propostas organizativas diferentes: Porto Alegre, o município do Rio de Janeiro e um município da Baixada Fluminense (Fetzner, 2007).
A análise desenvolvida utiliza o conceito de cultura escolar para percepção das práticas encontradas e indica elementos de transição cultural, política e pedagógica nos cotidianos escolares pesquisados.

\section{Sociedade e cultura escolar}

Os fazeres docentes, assim como as práticas familiares e as demais relações sociais estabelecidas, não estão descolados de uma realidade social e cultural que os conforma. Ao mesmo tempo, a família, a escola e as relações de trabalho não apenas reproduzem a sociedade e a cultura onde são geradas, mas, ao reproduzirem-nas (a sociedade e a cultura a que pertencem), transformam-nas.

Nesse movimento, que é simultaneamente de reprodução e de transformação, encontramos a estrutura escolar existente, com seus rituais (fila, chamada, ordenamentos temporais e outros), e, ao mesmo tempo, uma nova estrutura que tenta se constituir por meio da ruptura com os tradicionais ordenamentos e rituais.

Para Viñao Frago (1995, p. 69), a cultura escolar contém práticas e condutas, modos de vida, hábitos e 
ritos, a história cotidiana do saber escolar, os objetos materiais, a função, o uso e a distribuição no espaço, a materialidade física, a simbologia, os modos de pensar, significados e ideias compartilhados. Porém, entre os elementos que mais organizam e conformam a cultura escolar, estão os espaços e tempos, as práticas discursivas e linguísticas ou as formas de comunicação:

Estas tres dimensiones o aspectos - el espacio, el tiempo y el lenguaje o modos de comunicación - afectam al ser humano de lleno, en su misma conciencia interior, en todos sus pensamientos y actividades, de modo individual, grupal y como especie en relación con la naturaleza de la que forma parte. Conforman y son conformados, a su vez, por las instituciones educativas. De ahí su importancia. (1995, p. 69)

A escola propõe regras, validações, punições que buscam moldar o sujeito educado. Os tempos, os espaços e a linguagem validados pela escola interiorizamse no sujeito, não apenas o instruindo intelectualmente, mas formatando seus valores e, em especial, os valores sobre si mesmo (Viñao Frago, 1995). Entre as regras que são propostas, a organização do tempo: entre os tempos de estudar e os tempos de brincar vê-se a valoração de atitudes que são consideradas estudo ou perda de tempo, relevantes ou irrelevantes, atividades produtivas ou improdutivas.

Observar a transformação da cultura escolar implica, portanto, identificar os valores que permeiam a organização dos tempos, espaços e linguagens em mudança nas práticas escolares.

Com a massificação do ensino, elegeu-se no Brasil, mais com base na tradição e na influência dos livros didáticos do que nas orientações curriculares nacionais, um conteúdo básico a ser trabalhado em todas as escolas, dividido entre as nove séries do ensino fundamental. Cada série escolar, portanto, apresenta um rol de conteúdos a serem assimilados pelos alunos.

A forma mais comum de repasse desses conteúdos sustenta-se na ideia de transmissão simultânea, pela qual um professor ou uma professora, em uma sala de aula, ensina um mesmo conteúdo, com as mesmas atividades, para todos os alunos ao mesmo tempo.
Ao final de um período de dois ou de três meses, esse professor ou professora avalia a aquisição desses conteúdos por meio de provas que resultam em notas ou conceitos.

O trabalho escolar compartimentado e repetitivo muitas vezes gera a alienação do professor sobre seu próprio trabalho: o professor vê os conteúdos que deve ensinar, em que ponto desses conteúdos se encontra e aonde deve chegar até o final do ano letivo. Direcionado para o ensino dos conteúdos, o professor tende a deixar de visualizar a educação das crianças de forma integral.

Em síntese: o modelo de organização escolar predominante no ensino fundamental, a organização seriada, prevê que as séries sejam formadas por um conteúdo que, diferente para cada série, seja ministrado em um mesmo tempo para todos os alunos. Ao propor isso, organizam-se um tempo padrão, currículos universais, avaliações padronizadas e uma didática que traduz o ensino como o ministrar de conteúdos, pelo professor, pela professora, para o conjunto dos alunos. ${ }^{2}$

Esses padrões de organização conformam o espaço e o tempo escolar, criam hábitos, valores e formas de comunicação, aspectos da cultura escolar que podem afirmar ou negar linguagens, saberes e culturas. $\mathrm{Na}$ hegemonia do conhecimento livresco sobre as práticas escolares (na tentativa de transmissão desses conhecimentos na forma de recitação e cópia, nos seus mais diversos sentidos), os saberes e, muitas vezes, a capacidade de aprender dos alunos são negados, assim como sua cultura e sua linguagem.

${ }^{2}$ Nem sempre as escolas seriadas organizam-se com esse padrão de tempo e práticas curricular, avaliativa e didática, embora essas características sejam predominantes. Da mesma forma, algumas escolas tidas como organizadas em ciclos também têm práticas semelhantes às escolas seriadas. O que se verifica, de modo geral, é a tentativa (ainda em processo) de as escolas em ciclos trabalharem coletivamente (coletivos de professores, alunos, comunidade e escola), tratarem o conhecimento escolar na forma de diálogo entre saberes da experiência dos alunos e conhecimentos acadêmicos, efetivarem práticas avaliativas coletivas, dialogadas, voltadas para o reconhecimento dos avanços do processo educacional. 
A sociedade brasileira tem-se configurado politicamente com alianças entre as camadas dirigentes conservadoras e as camadas médias da população, que, aliadas aos valores conservadores, efetivam um Estado que alija as classes populares dos direitos que constituem a cidadania (Vieira \& Freitas, 2003). Essa configuração política reflete-se também na construção de uma cultura escolar que afirma linguagens, culturas e saberes adequados ao sucesso escolar das camadas dirigentes e médias da população desde há muito tempo.

Por mais difícil que nos pareça, ainda hoje, a educação como um processo que possa afirmar valores de emancipação às camadas populares, as experiências de desenvolvimento dos conceitos de educação integral (anos de 1920), educação popular (final dos anos de 1950 e início dos anos de 1960) e ciclos (anos de 1990) foram algumas das que registraram a construção possível de propostas alternativas que afirmam a escola como espaço de vivência da cidadania, da pluralidade de saberes e de trocas culturais.

O ensino primário de quatro anos, por exemplo, no período da Primeira República (tempo em que os concluintes do ensino fundamental eram cerca de 13\% dos matriculados) foi alvo de tentativas de mudança: buscando possibilitar a conclusão do ensino primário por uma maior parcela da população, várias reformas pedagógicas tentavam implementar a Escola Primária Integral: Lourenço Filho, Ceará, 1923; Anísio Teixeira, Bahia, 1925; Francisco Campos e Mário Cassasanta, Minas, 1927; Fernando de Azevedo, Distrito Federal, 1928; Carneiro Leão, Pernambuco, 1928.

Comentando a reorganização da instrução pública na Bahia promovida por Anísio Teixeira, Moreira (2007, p. 88) diz:

[...] Novas perspectivas em relação ao currículo eram evidentes na reorganização da instrução pública na Bahia, promovida por Anísio Teixeira. Pela primeira vez, disciplinas escolares foram consideradas instrumentos para o alcance de determinados fins, ao invés de fins em si mesmas, sendo-lhes atribuído o objetivo de capacitar os indivíduos a viver em sociedade. Tal concepção implicou a ênfase não só no crescimento intelectual do aluno, mas também em seu desenvolvimento social, moral, emocional e físico.

O ideário da Escola Primária Integral propunha desenvolver um ensino que, adaptado à realidade sociocultural dos alunos, oportunizasse um conjunto de conhecimentos e habilidades básicas, como literatura, história pátria e manejo da língua como instrumento de pensamento e expressão, entre outros (Bahia, 1925). A motivação da proposta orientava-se por superar o ensino "livresco", descolado da realidade circundante e ministrado em uma linguagem de pouco acesso às crianças das camadas populares. Esse conceito inspirará o Manifesto dos Pioneiros da Educação Nova, em $1932 .^{3}$

Outros exemplos de movimentos que tentaram alterar a lógica hegemônica de organização escolar entre 1958 e 1964 foram: a campanha De Pé no Chão também se Aprende a Ler, promovida pela Prefeitura de Natal, e o Movimento de Educação de Base, organizado pela Igreja católica. Essas duas experiências tinham em comum o conceito de educação popular, no sentido de uma ampliação da preparação do povo, tanto para a vida como para o trabalho, com base em uma formação política e na valorização dos saberes da cultura popular. Para a campanha, por exemplo, a alfabetização deveria ter como objetivo máximo:

\section{[...] integrar o educando na sua comunidade, dando para isso a oportunidade de sentir e viver a cultura do seu povo [...]. Tal integração deve ter como sentido uma profunda vivência com a problemática da terra, de tal forma que o aluno sinta a realidade regional, estadual e nacional e reflita sobre tais problemas [...]. A integração da criança ao meio deve ser atingida através do próprio conteúdo do ensino. Assim é que todo o currículo deve ser desenvolvido através}

${ }^{3}$ Nos anos de 1980 e 1990, no Rio de Janeiro, a experiência dos Centros Integrados de Educação Pública (CIEP) retomou o ideário da Escola Integral, propondo que a escola compreendesse e trabalhasse com o aluno, integradamente, suas dimensões de bemestar físico (saúde, alimentação, higiene), seu desenvolvimento social, cultural e político (Cavaliéri, 1996). 
de grandes temas que procurem dar ao aluno uma visão de conjunto com uma interpretação de suas implicâncias no setor social. (Secretaria de Educação, Cultura e Saúde de Natal, in Germano, 1982, p. 144)

A educação popular traz, portanto, uma proposta de ruptura com o ensino conservador e excludente, propondo uma escola que se faça com o povo e para o povo, na defesa de seus direitos e saberes (Freire, 1975). Os fazeres na organização dessas práticas: o diálogo com a comunidade, práticas curriculares e avaliativas coletivas, ordenação dos espaços e tempos em acordo com as necessidades avaliadas pelo grupo seriam as bases do surgimento de outra cultura escolar.

Nesse debate, muito contribuiu Paulo Freire. Sua crítica radical ao "ensino bancário" e sua proposta de educar desde uma perspectiva crítica de mundo, por meio do engajamento do ensino à realidade, feitas no final dos anos de 1950 e início dos anos de 1960, reaparecem anos mais tarde, após a ditadura militar no Brasil, e têm influência na organização escolar em ciclos, implementada em sua gestão como secretário de Educação no município de São Paulo (1989-1992). Os ciclos, no entendimento trazido neste trabalho, consistem no desdobramento das práticas de democratização da escola, a serem explicitadas numa articulação entre os conceitos de participação e necessidades de desenvolvimento humano.

\section{Ciclos e democratização da educação}

Ao final do último século, no Brasil, alguns conceitos de ciclos começaram a aparecer em diferentes organizações escolares. Entre esses conceitos, podem ser identificados:

a) Ciclos de alfabetização (década de 1980), proposta na qual, durante o período inicial do ensino fundamental, entendido como o período de aprender a ler e a escrever, não há reprovação escolar. Baseado no entendimento de que a repetição da rotina de trabalho na primeira série escolar seria desnecessária e nociva para os alunos que já cursaram esse ano, mesmo que eles ainda não tenham aprendido a ler e escrever como esperado, os ciclos básicos de alfabetização propunham a promoção continuada durante os primeiros dois anos de escolaridade, período em que a criança deveria ser atendida considerando suas necessidades específicas de mediação no processo de alfabetização (Mainardes, 2007; Barretto \& Mitrulis, 2004).

b) Ciclos de aprendizagem (meados da década de 1990), ${ }^{4}$ proposta que prevê revisão curricular no ensino fundamental acompanhada de extensão do tempo para que os alunos possam adquirir os conhecimentos previstos pela escola. Nos ciclos de aprendizagem, mantém-se certa referência aos conteúdos da série; um exemplo disso são os Parâmetros Curriculares Nacionais, que propõem ciclos que conservam ou agrupam duas séries escolares cada um: Ciclo I, $1^{\text {a }}$ e $2^{\text {a }}$ séries; Ciclo II, $3^{\text {a }}$ e $4^{\text {a }}$ séries; Ciclo III, $5^{\text {a }}$ e $6^{\text {a }}$ séries, Ciclo IV, $7^{\mathrm{a}}$ e $8^{\mathrm{a}}$ séries (Brasil, 2005a).

c) Ciclos de formação (anos de 1990 até hoje), proposta de enturmação escolar em que não mais se agrupam os alunos de acordo com um pretenso conhecimento anterior adquirido. A

${ }^{4}$ Mainardes (2007) afirma que os ciclos de aprendizagem geralmente propõem rupturas menos radicais no que se refere a currículo, avaliação, metodologia e organização. Entendo que essa menor radicalidade coloca-se no fato de que, ao final de cada ciclo de aprendizagem, os alunos somente são promovidos ao ciclo seguinte quando atingiram os objetivos do ciclo, ou seja, podem ser reprovados ao final de cada ciclo de aprendizagem. A existência da reprovação escolar (a possibilidade de repetência no último ano do ciclo de aprendizagem) demonstra que o critério de assimilação dos conteúdos em um determinado tempo permanece, assim como o entendimento de que os conteúdos a serem assimilados são trabalhados apenas naquele ciclo. Essas são referências do currículo graduado ou seriado. 
enturmação escolar segue o critério de aproximação das idades dos alunos, considerando como referência as potencialidades e características que o aluno apresenta em diferentes fases de sua vida (infância, pré-adolescência e adolescência). Na prática, o aluno entraria em uma turma escolar e permaneceria nela até o final do ensino fundamental. As experiências mais conhecidas foram nas administrações populares no município de São Paulo (tendo Paulo Freire como secretário de Educação), de Belo Horizonte (Escola Plural), e em Porto Alegre (Escola Cidadã). Recentemente, o município do Rio de Janeiro, que em 2006 possuía 591.741 matrículas no ensino fundamental (dados do Instituto Nacional de Estudos e Pesquisas Educacionais Anísio Teixeira - INEP), ampliou a organização em ciclos nas escolas: desde 2000 o município possuía o ensino fundamental em ciclos nos primeiros três anos de escolarização e, em 2007 (sob a administração do Partido dos Democratas), propôs o segundo e terceiro ciclos, também com três anos de duração cada ciclo.

Essa enturmação escolar considera que o desenvolvimento humano é decorrente das mediações provocadas pelo meio sociocultural (do qual a escola é um dos elementos) em relação dialética com o desenvolvimento biológico:

\footnotetext{
a chave para entender a psicologia das idades se encontra no problema da orientação, no problema das forças motrizes, na estrutura das atrações e aspirações da criança. Os mesmos hábitos, os mesmos mecanismos psicofisiológicos da conduta, que desde um ponto de vista formal não demonstram diferenças essenciais nas distintas etapas da idade, inserem-se, em diversas etapas da infância, em um sistema de aspirações completamente distinto, com uma orientação de todo diferente e daqui surge a profunda peculiaridade de sua estrutura, de sua atividade e suas trocas em uma dada etapa da infância. (Vygotsky apud Krug, 2001, p. 29)
}

Vygotsky (1996) define desenvolvimento como um processo contínuo de automovimento marcado pela permanente aparição e formação do novo e de possibilidades de relação e ação não existentes em estágios anteriores. A abordagem vygotskyana associa os conceitos de idade de formação e contexto de desenvolvimento, expressando a unicidade entre o social e a personalidade. A mudança das orientações da ação e do pensamento humano em diferentes fases da vida sofre influências das mudanças biológicas e, ao mesmo tempo, do mundo social e cultural a que pertencemos.

Nessa perspectiva, para a escola, por exemplo, alfabetizar uma menina de sete anos é um processo no qual seria imprescindível percebê-la na vivência dos seus sete anos, assim como alfabetizar um adolescente de quatorze anos exigiria percebê-lo enquanto uma pessoa que tem quatorze anos. Os desafios cognitivos, afetivos e motores a serem enfrentados por esses estudantes são diferentes dos pontos de vista biológico, social e cultural e exigem, por consequência, mediações diferentes no que se refiram à organização: do espaço físico, das atividades a serem propostas e das temáticas a serem estudadas. Mobilizar para a aprendizagem alunos em diferentes idades exige diferentes provocações.

O estudo das idades-crise e das idades estáveis como fases de mudança nas orientações das ações e dos pensamentos das crianças contribui para o entendimento dos ciclos escolares que propõem agrupar crianças entre seis e oito anos em um primeiro ciclo, nove e onze anos em um segundo ciclo e doze a quatorze anos em um terceiro ciclo (Krug, 2001). Compreender as relações entre o desenvolvimento biológico, social e cultural das crianças e as propostas educativas escolares pode ser útil na qualificação dessas propostas, superando o entendimento de que os alunos se apropriam do conhecimento escolar de forma linear e pela repetição (ou recitação) de conhecimentos.

Wallon é também um referencial para o entendimento do agrupamento etário. Seu trabalho destaca a importância de que a mediação das aprendizagens escolares considerem as potencialidades apresentadas pela idade do aluno e as formações novas: "cada idade tem suas modalidades próprias de adaptação, que 
constituem a fórmula ótima de utilização do repertório atual de meios comportamentais” (Werebe \& NadelBrulfert, 1986, p. 13).

Como Vygotsky, Wallon considera que cada idade tem novas finalidades, ligadas a novas potencialidades funcionais emergentes e aos novos campos de atividades disponíveis (idem, ibidem). A consideração de que educar exige que reconheçamos os desafios biológicos, sociais e culturais e as potencialidades que se apresentam diferentes a cada idade não prescinde de que, a cada agrupamento escolar, façamos uma avaliação dos saberes e não-saberes, das construções cognitivas, afetivas e motoras já processadas e das necessidades emergentes. Mas a forma pela qual se define o agrupamento escolar (turma) é diferente: não mais orientada pelo conhecimento anterior adquirido (expresso pelo alcance da média escolar nas provas finais ou pela colocação dos que mais sabem determinado conhecimento em separado dos que menos sabem), e sim pelo direito da vivência de sua idade na escola, o que, para Wallon, é importante também para o desenvolvimento da personalidade (reconhecer-se semelhante e diferente de seus pares).

Reconhecer as diferenças biológicas, sociais e culturais decorrentes das idades também não significa que nos agrupamentos etários (com base em aproximação das idades) todos os alunos são iguais, têm todos os mesmos interesses e, muito menos, os mesmos saberes. O agrupamento etário toma como princípio o trabalho com turmas heterogêneas em conhecimento. Nesse ponto, tanto o agrupamento escolar seriado quanto o agrupamento por idades aproximadas resultam em turmas em que o conhecimento dos alunos é heterogêneo. A diferença é que no primeiro caso (seriado) essa diferença é considerada um incômodo, um erro da avaliação escolar que deveria resultar no agrupamento dos alunos segundo o conhecimento anterior adquirido. No agrupamento etário - organizado tendo por base os ciclos de desenvolvimento humano - a heterogeneidade é tomada como um princípio para as aprendizagens da turma, considerada um potencializador dos grupos de trabalho. A mediação entre colegas ${ }^{5}$ é fundamental para

${ }^{5}$ Sobre sistema de tutorias, ver Duran (2008). ampliar as aprendizagens que a escola oferece.

De um total aproximado de 33 milhões de matrículas no ensino fundamental (sistemas públicos e privados de ensino) em 2006, apenas seis milhões funcionavam em regimes de ciclos; cerca de quatro milhões estavam em regimes que conjugavam séries e ciclos; as demais matrículas eram em regimes exclusivamente seriados (Brasil, 2008b).

Considerando a realidade social e econômica brasileira, desigual e excludente, ${ }^{6}$ não é difícil imaginar o quanto é desafiadora, para professoras e professores, uma escola que se contraponha àquela que é hoje hegemônica, uma escola que se organize por meio da afirmação da capacidade de aprender e dos conhecimentos que os alunos trazem, sua linguagem, suas formas de ver o mundo, para, em diálogo, construir e desconstruir visões. Tudo isso imerso nas enormes dificuldades enfrentadas pela falta de suficiente investimento público na educação, salários não condizentes com o trabalho a ser desenvolvido, falta de recursos pedagógicos adequados, carência de práticas de gestão democrática dos sistemas públicos e das escolas, salas de aula com muitos alunos por professor.

Além das dificuldades decorrentes da desigualdade social e das condições objetivas do trabalho escolar (materiais, salários, formação), a proposta de ciclos e o processo de democratização da educação escolar estão imersos em uma sociedade conservadora:

O processo de democratização enfrenta a falta de referências significativas de prática democrática na sociedade brasileira. O caráter excludente e autoritário da nossa sociedade, o processo de apropriação privada do aparelho do Estado pelas elites, a luta pela democracia e a reação conservadora agregam ao espaço escolar um lócus fundamental [...]. (Azevedo, 2007, p. 150)

${ }^{6}$ Dados de 2005 indicam que os $10 \%$ mais ricos do país detêm $75 \%$ da renda nacional, resultando que os $90 \%$ mais pobres compartilhem 25\% dessa renda. Das 60 milhões de famílias brasileiras, 5 mil ficam com $45 \%$ da renda e riqueza nacional. Entre 1979 e 2005, a participação do trabalho na renda nacional caiu 12\% (Pochmann, 2007). 
Na luta pela democratização da sociedade, a democratização escolar pode ser entendida em três dimensões: a democratização do acesso à educação (Azevedo, 2000, 2007; Paro, 2001; Ghanem, 2004), a democratização da gestão da educação (idem) e a democratização do conhecimento (Azevedo, 2000, 2007; Gandin, 2008).

Por democratização do acesso à educação entende-se a ampliação da população atendida pelas escolas: crianças, jovens e adultos que tem respeitado seu direito de acesso à escola básica e à formação intelectual e técnica necessária para a ampliação de seus conhecimentos e para a inserção crítica e ativa no mundo do trabalho.

A democratização da gestão da educação é entendida buscando a participação do povo na construção e implementação do projeto escolar. A democratização do conhecimento, por sua vez, significa tanto o acesso a uma educação de qualidade, portanto, que trabalhe com conhecimentos substantivos para a formação do cidadão, quanto a democratização do próprio conceito de conhecimento, incluindo os saberes populares.

Como diz Paro (2001, p. 18):

\footnotetext{
Esse exercício [da liberdade] é que se constitui na própria democracia como mediação para a liberdade. Por isso é que se diz que a democracia é ao mesmo tempo meio e fim, posto que sua realização (uma mediação) consubstancia-se na própria realização da liberdade, não como apenas uma palavra, mas como algo concreto que é a própria realização do homem em sua especificidade histórica.
}

Tratarei, a seguir, da especificidade da proposta de ciclos na rede municipal de Porto Alegre, uma proposta que tentou incorporar os princípios da democratização à cultura escolar.

\section{Porto Alegre: participação popular e ciclos de formação}

Em Porto Alegre, os ciclos de formação foram implementados como desdobramento das políticas de democratização da cidade: em 1989, a coligação parti- dária Frente Popular ${ }^{7}$ assumiu o governo declarandose identificada com forças políticas comprometidas com a necessidade de transformação das condições sociais e econômicas excludentes impostas à maioria da população.

Na tentativa de transformar as condições sociais e econômicas excludentes, a Administração Popular desenvolveu o Orçamento Participativo (OP), que estabeleceu um movimento de diálogo direto entre população e governo (dispensando a mediação da Câmara de Vereadores para atendimento a necessidades e obtendo melhorias na cidade). Esse diálogo teve como foco a elaboração dos orçamentos anuais, a fim de definir os investimentos a serem realizados de acordo com as demandas da população. Para elaboração do orçamento, criaram-se assembleias regionais de discussão, com participação direta do governo municipal e da comunidade, em que eram indicadas pela população suas demandas e funcionavam como fóruns de acompanhamento da aplicação do orçamento:

\begin{abstract}
O Orçamento Participativo (OP) não é apenas um exercício de divisão das receitas e das despesas municipais pela própria população. Por causa de sua amplitude - a metrópole conta com 1,3 milhão de habitantes, no coração de uma região metropolitana de 3,3 milhões - e pelo seu método, rigoroso e evolutivo, ele constitui uma experiência de democracia direta sem equivalente no mundo. (Cassen, 1998, p. 4)
\end{abstract}

Com área territorial de $497 \mathrm{~km}^{2}$, Porto Alegre apresentava em 2000 um PIB per capita de R\$15.577,00 (Brasil, 2008a); sua economia estava baseada em serviços, com 56,48\% dos estabelecimentos gerando 73,08\% dos empregos, e no comércio, com 31,65\% dos estabelecimentos gerando 14,35\% dos empregos (Brasil, 2005b). A rede municipal de ensino de Porto Alegre possuía cerca de 44 mil alunos e 3.800 professores (Brasil, 2008b).

\footnotetext{
${ }^{7}$ A Frente Popular, liderada pelo Partido dos Trabalhadores,
} governou a cidade de Porto Alegre entre 1989 e 2004. 
O programa do Partido dos Trabalhadores se propunha à prática da democracia, acreditando que esta seria, "a um só tempo, meio e fim, instrumento de transformação e meta a ser alcançada” (Löwy, 1999, p. 496-497).

A prática de, em cada pequena região da cidade, os moradores apresentarem aos governantes suas prioridades e, assim, influírem na definição de investimentos, obras e políticas setoriais, além de instrumentalizar a população para lidar com a peça do orçamento público, diminuiu a possibilidade de corrupção e de má aplicação do dinheiro.

Navarro (1997), ao pesquisar sobre os impactos políticos do OP, apontou:

a) forte redução das práticas clientelistas por parte dos vereadores da Câmara Municipal, pois a população não precisava mais se submeter à avaliação da validade de suas reivindicações por vereadores;

b) a percepção, pela população, dos resultados alcançados nas regiões e da relação entre "bons resultados" e "bons delegados", ${ }^{8}$ construindo a noção de representação como valor social de sustentabilidade política;

c) redução dos desejos emancipacionistas em diversas regiões da cidade;

d) construção de canais diretos de comunicação e negociação das comunidades mais empobrecidas com as autoridades municipais e instrumentalização dessas comunidades para tratamento de temas complexos como orçamento e seus mecanismos;

e) política salarial do funcionalismo municipal e valorização do serviço prestado por ele à população, obtidos por meio da relação direta entre o funcionalismo e os grupos sociais envolvidos com o Orçamento;

${ }^{8}$ Os delegados do OP eram eleitos por seus pares nas assembleias regionais e a eles competia acompanhar todo o processo, inclusive a execução do orçamento. f) desperdícios evitados em obras públicas, por meio da fiscalização da população às obras;

g) transparência da administração na alocação e disponibilidade de recursos;

g) reversão do conjunto tradicional de prioridades, provocando a transferência de recursos para as áreas mais pobres da cidade.

Do ponto de vista pedagógico, o Orçamento Participativo também possibilitou o exercício da cidadania na dimensão do exercício político: ao discutir coletivamente seus problemas, a comunidade construía sua articulação, os problemas deixavam de ser individuais e passavam a ser contextualizados nas necessidades coletivas (Krug, 2001).

Entre os desafios do OP, pesquisadores como Navarro (1997) indicavam o conflito entre democracia representativa e a estrutura de democracia direta proposta pelo OP. No centro desse conflito, os vereadores da Câmara Municipal viram seu poder político diminuir e, nessa disputa, tentavam regulamentá-lo.

Em 1989, na primeira gestão da Administração Popular (1989-1992) em Porto Alegre, o projeto educacional desenvolvido na cidade promoveu a recuperação salarial dos professores e das professoras e a qualificação da rede física das escolas, além de ampla formação continuada em serviço, em especial na discussão do construtivismo. Após essas medidas, os índices de reprovação escolar e evasão permaneciam, respectivamente, em 22\% e 5\% (Azevedo, 1999; Krug, 2001; Fetzner, 2007).

Foi somente na segunda gestão da Administração Popular que o conceito de gestão democrática foi incorporado pela Secretaria Municipal de Educação; portanto, o movimento de democratização que se constituía por meio do OP na cidade estava agora presente na discussão educacional. Nessa segunda gestão, o projeto Escola Cidadã se desenvolveu tendo como base a criação de canais de participação e de decisão na escola (os conselhos escolares) a implementação do Conselho Municipal de Educação, a reestruturação da Secretaria Municipal, a eleição direta de diretores e vice-diretores das escolas de forma paritária (entre 
professores e funcionários, pais e alunos) e a Constituinte Escolar (Pilla Vares, 1996; Azevedo, 1999).

Na reestruturação da Secretaria Municipal de Educação realizou-se a reorganização interna, colocando a atividade-meio, a administrativa, a serviço da atividade-fim, a pedagógica (Azevedo, 1999). Nessa reorganização, diminuíram-se os níveis de hierarquia internos da secretaria, fundamental para a criação de canais diretos de participação da escola na secretaria e da secretaria na escola, esta última efetivando-se na figura dos assessores escolares (Azevedo, 1999, 2000, 2007; Krug, 2001).

O processo de eleição direta de diretores e vicediretores de escola envolveu a elaboração coletiva da proposta e a formação específica dos eleitos para a gestão após a eleição e formação, por categoria, de funcionários, alunos, pais ou responsáveis pelos alunos e professores para participação nos conselhos escolares, os quais se constituíram no órgão máximo de deliberação das escolas. Na eleição de diretores e vice-diretores, os votos dos alunos e de suas famílias tinham o mesmo valor que os votos dos professores e professoras e funcionários e funcionárias de escola.

Constituinte Escolar foi o processo pelo qual foram construídos os princípios orientadores da Escola Cidadã. Esses princípios definiram a orientação quanto à gestão democrática, ao currículo escolar, à avaliação e aos princípios de convivência na escola (Azevedo 2000; SMED, 2000; Krug, 2001; Rocha, 1996). Esse processo iniciou-se em 1993, com reuniões por categorias (alunos, pais e responsáveis, professores e funcionários) em cada escola municipal, discutindo os quatro eixos do congresso: gestão, currículo, avaliação e convivência escolar. Ao fazer essa discussão, cada grupo respondia qual escola tinha e qual escola desejava quanto a esses eixos.

Nas discussões por escola, elegiam-se os representantes para as reuniões regionais, em que foram construídos os princípios da Escola Cidadã, depois levados para o Congresso Constituinte Escolar, em 1994, o qual contou com a representação de todas as categorias de quase todas as escolas da rede (duas escolas optaram por não participar). Desse congresso resultaram os 98 princípios da Escola Cidadã. Entre esses princípios, destacam-se:

\section{Quanto à gestão:}

Princípio 1 - A construção da gestão democrática na escola passa pela garantia da participação de todos os segmentos nas decisões e encaminhamentos.

Quanto ao currículo:

Princípio 27 - O papel do educador é colocar-se junto ao aluno, problematizando o mundo real e imaginário, contribuindo para que se possa compreendê-lo e reinventálo, crescendo e aprendendo junto com o aluno, tentando vivenciar com ele seus conflitos, invenções, curiosidades e desejos, respeitando-o como um ser que pensa diferente, respeitando a sua individualidade.

Quanto à avaliação:

Princípio 56 - Na avaliação do aluno, ele é parâmetro de si mesmo.

Quanto à convivência:

Princípio 78 - Convivência centrada no respeito mútuo, garantindo a livre expressão e argumentação em igualdade de condições entre: comunidade escolar; comunidade escolar e mantenedora; comunidade escolar e órgãos/entidades afins. (SMED, 2000)

Em Porto Alegre, a implementação das escolas em ciclos foi gradual, começando com a Escola Municipal Monte Cristo, em caráter experimental. Essa escola, por ser nova e demandada pela comunidade por meio do OP, optou por elaborar um regimento escolar novo, já experimentando a vivência dos princípios que eram aprovados no Congresso Constituinte. Essa experiência foi ampliada pela secretaria para as escolas novas em 1996 (Escolas Municipais Migrantes, Neusa Brizola e Morro da Cruz) e, desde 1997, para as escolas que aprovassem participar da experiência (Azevedo, 2000; Krug, 2001; Fetzner, 2007).

As práticas encontradas no estudo de campo realizado nessa rede de ensino compreendiam:

a) planejamento coletivo entre os anos de escolarização, sendo o currículo organizado 
pela própria escola, por meio do complexo temático, ${ }^{9}$ que partia de uma pesquisa socioantropológica ${ }^{10}$ que indicava os conceitos fundamentais de cada área de conhecimento a serem abordados, de acordo com as potencialidades do desenvolvimento das crianças, pré-adolescentes ou adolescentes, o que difere radicalmente do currículo seriado, em que os conhecimentos são previamente distribuídos por série;

b) organização dos tempos escolares de forma contínua, com horários mais extensos e não tão compartimentados entre as disciplinas como nas escolas seriadas e com aulas organizadas na perspectiva interdisciplinar, procurando oferecer ao aluno um todo coerente;

c) espaços de aprendizagem diferenciados, tentando atender às necessidades específicas dos alunos para seu desenvolvimento cognitivo, afetivo e motor e garantindo o atendimento escolar necessário para o desenvolvimento de todos nas melhores condições possíveis (laboratórios de aprendizagem, salas de artes, informática educativa), serviços estes providos pelo Estado e não por parcerias com a iniciativa privada, organizações não confessionais ou serviços voluntários;

${ }^{9}$ Os complexos temáticos eram formas de organizar coletivamente intra e interciclos o currículo escolar (ver Rocha, 1996; Krug, 2001; Fetzner, 2007) e integrar os estudantes e suas famílias na discussão do currículo escolar e as áreas de conhecimento no desenvolvimento dos estudos a serem realizados.

${ }^{10}$ Chamava-se pesquisa socioantropológica, na Rede Municipal de Ensino de Porto Alegre, a pesquisa realizada na comunidade escolar para identificar problemas a serem trabalhados na escola; por meio desses problemas, os conhecimentos das áreas de estudo eram articulados, sem referência a currículo único a ser desenvolvido na rede. O que identifica o currículo na Rede Municipal de Porto Alegre são os princípios curriculares aprovados no Congresso Constituinte Escolar. d) aulas que se organizavam priorizando o trabalho em grupo, a troca de experiências e saberes entre os alunos e a ajuda mútua;

e) práticas avaliativas coletivas, participativas e direcionadas para a reorganização das atividades, a busca de suporte adequado ao ensino e direcionadas ao conjunto da escola.

A escola pesquisada em Porto Alegre foi a Escola Municipal Wenceslau Fontoura, no bairro Rubem Berta. Essa escola atendia alunos de um reassentamento urbano extremamente empobrecido. Tratava-se, na avaliação da Secretaria Municipal de Educação, de uma escola com bom entendimento da proposta e com o quadro de pessoal e recursos físicos dentro do previsto para o projeto. Em 2003, ano da pesquisa de campo, ela atendia 1.210 alunos, distribuídos em 41 turmas, contando com 76 professores. A escola oferecia (como é comum naquela rede) os três ciclos de formação (ensino fundamental completo), duas turmas de educação infantil (com crianças de cinco anos) e educação de jovens e adultos à noite. Como estruturas de apoio, a escola dispunha de biblioteca, telecentro, ${ }^{11}$ laboratório de aprendizagem ${ }^{12}$ e professores itinerantes. ${ }^{13}$

Essa escola começou a funcionar em 1993 como escola aberta, ou seja, destinada ao atendimento de meninos e meninas em situação de rua. Esse trabalho buscava oferecer a possibilidade de escolarização sem

${ }^{11}$ Espaço informatizado com acesso à Internet, aberto à comunidade.

${ }^{12}$ Espaço de apoio ao ensino e à formação docente. Ao trabalhar, no contraturno das aulas, com estudantes que apresentavam maior dificuldade nos estudos, o laboratório produzia informações a serem repassadas aos professores nos espaços coletivos de formação, buscando atender às necessidades específicas dos alunos no conjunto das aulas comuns.

${ }^{13}$ Professores que trabalhavam junto com os demais no atendimento da turma, acrescidos na proporção de um professor a mais para cada três turmas do primeiro ciclo, um para cada quatro do segundo ciclo e um para cada cinco turmas no terceiro ciclo (em média). 
as formalidades de uma escola regular no que se refere ao cumprimento dos tempos escolares. Transformouse em escola regular em 1995, organizada em etapas, o que permitia maior flexibilidade do tempo para que os alunos circulassem entre as etapas da escolarização, de forma independente do tempo em que cursassem um ano letivo e sem a utilização de notas ou conceitos como expressão dos resultados de avaliação. Os ciclos foram implementados em 1997 por opção dos segmentos escolares (professores, funcionários, estudantes e famílias).

As salas de aula visitadas na pesquisa organizavam-se em grupos de trabalho. Para a equipe diretiva da escola e para os docentes entrevistados, ${ }^{14}$ os ciclos representavam oportunidades de trabalho interdisciplinar e coletivo e significativa liberdade para que criassem suas propostas, metodologias de trabalho e buscassem conteúdos escolares novos.

Como dificuldade, os professores da escola entrevistados indicavam diversos aspectos. Não havia discurso comum quanto às necessidades de mudança na proposta de ciclos. Uma professora colocou como centro de suas críticas a não-reprovação escolar durante o terceiro ciclo, pois esse seria o período mais difícil na relação professor-aluno; outra professora criticou a forma como algumas colegas trabalham com os alunos com maior dificuldade nas aulas comuns, deixando-os de lado, para que outros profissionais dessem conta do ensino. As sugestões, tanto da equipe diretiva quanto dos professores entrevistados, dirigiam-se a necessidades de aperfeiçoamento do serviço oferecido pela escola: aulas de reforço em química, biologia e física para alguns dos alunos egressos que cursavam o ensino médio ${ }^{15}$ apresentando necessidades de apoio nessas disciplinas; um trabalho mais efetivo da coordenação pedagógica no acompanhamento das dificuldades específicas dos docentes.

\footnotetext{
${ }^{14}$ Foram entrevistados nesta escola cinco docentes, considerados pela direção os mais resistentes à proposta de ciclos.

${ }^{15}$ Por iniciativa da vice-direção, a escola realizava levantamento sobre o desempenho dos egressos no ensino médio (Fetzner, 2007).
}

Destacam-se, na implementação da proposta de ciclos em Porto Alegre: a participação das escolas na escolha por implementar a proposta; a orientação da organização do ensino em complexos temáticos, por meio da pesquisa socioantropológica e, em especial, a pouca resistência geral à proposta. Enquanto em outros municípios estudados (Fetzner, 2007) algumas falas docentes diziam que a proposta de ciclos buscava desqualificar a escola que atenderia aos pobres, em Porto Alegre o projeto era percebido dentro de um movimento de inclusão social, do qual a escola era um dos elementos:

\begin{abstract}
Os ciclos vão ao encontro de coisas que foram feitas para melhorar a vida de uma população que há milhares de anos foi excluída. Levar o ensino a lugares mais afastados. Às vezes nem esgoto tem, mas a escola está lá. Os ciclos completam o amparo a uma comunidade excluída de tudo. Amparo a um processo de não-exclusão. (Depoimento oral, dezembro de 2003)
\end{abstract}

Foi possível perceber, nas práticas e entrevistas realizadas em Porto Alegre, a incorporação da participação na cultura escolar. Essa incorporação como prática e valor da escola pode ter sido resultado dos vários movimentos de participação popular: Orçamento Participativo, Congresso Constituinte Escolar, Conselhos Escolares, da interlocução direta entre secretaria e escola durante o processo de implementação do projeto e pela criação de processos de participação na organização do currículo da escola.

Para Gandin (2008, p. 229):

A transformação curricular é uma parte crucial do projeto de Porto Alegre para construir uma cidadania ativa. É importante dizer que essa dimensão não se limita ao acesso ao conhecimento tradicional. O que também se estava construindo era uma nova compreensão epistemológica sobre o que conta como conhecimento, que não se baseia na simples incorporação de novo conhecimento nas margens de um intocado “centro de sabedoria da humanidade”, mas em uma transformação radical. O projeto da Escola Cidadã vai além da simples menção episódica de manifestações 
culturais ou da opressão baseada na classe, na raça, no sexo e no gênero, e inclui estes temas como uma parte essencial do processo de construção do conhecimento.

Estudo recente fortalece a observação de Gandin: analisados os complexos temáticos de três escolas da rede de Porto Alegre, foi possível perceber que o movimento curricular provocado pelos complexos temáticos resultava de uma seleção sobre o que trabalhar construída em diálogo com a comunidade e que as seleções analisadas apresentavam recorrência aos estudos sobre diferenças individuais, desigualdades sociais, identidades, discriminações e sexualidade, enfim, temas que sugerem estar o currículo escolar aberto à diversidade, à diferença e ao cruzamento de culturas (Fetzner, 2008).

A cultura escolar percebida na pesquisa realizada na escola em Porto Alegre demonstrou-se em mudança: as construções de possibilidades de trabalho aconteciam em diálogo entre as famílias e a escola e entre a comunidade escolar e a Secretaria de Educação. Naquela realidade, a discussão da implementação dos ciclos era para além da organização de tempos e espaços escolares de forma mais democrática e inclusiva. Os ciclos se constituíam, no caso estudado, como um mobilizador de transformações das relações estabelecidas na escola, representadas também nos temas tratados no currículo escolar.

Buscando a perspectiva de uma mudança escolar que possibilite a todos os estudantes o acesso, a permanência e a aprendizagem na escola, o estudo realizado com o olhar sobre a cultura escolar possibilitou perceber, nas práticas da escola, na organização das condutas, o saber escolar (o que é considerado saber e o que não é) e, em especial, os significados e as ideias compartilhadas (Viñao Frago, 1995), a indicação de que é possível e necessário transformar a escola em um espaço democrático de aprendizagem. Essa transformação passa por uma construção coletiva de princípios para a ação, e, nesse coletivo, necessariamente se incluem os estudantes e suas famílias e os conhecimentos docentes e discentes.

Esta pesquisa também possibilitou perceber que a escola organizada em ciclos não é pioneira no país entre as tentativas de democratização escolar, mas se encontra em um campo da política educacional que aponta a escola como espaço de desenvolvimento intelectual, moral, emocional e físico (não o único campo, pois a família e a sociedade também constituem esses campos) - tal qual a proposta de Escola Primária Integral propôs no Brasil dos anos de 1920 - e como um espaço que precisa dialogar com os movimentos populares, afirmando seus conhecimentos e colocando em interação os saberes da experiência e os saberes acadêmicos. Não se trata apenas de ampliar os tempos escolares ou de reorganizar os espaços para o trabalho com o conhecimento escolar por meio dos serviços de apoio ao ensino, por exemplo. No estudo realizado, a Escola Primária Integral, a educação popular e os ciclos implicam a redefinição do que seja conhecimento escolar e a transformação da cultura escolar: de práticas individualizantes, fragmentadas e reprodutivas para práticas mais dialogadas, coletivas e engajadas em um projeto de emancipação.

Como já apresentado por Barretto e Sousa (2004) no estudo sobre ciclos e progressão escolar no Brasil:

\footnotetext{
Os ciclos procuram romper com a fragmentação causada pela seriação, mas vão além, pois demandam mudanças no entendimento do que é conhecimento e aprendizagem, na ordenação do espaço e do tempo escolar, bem como na própria função da educação escolar, vindo a constituir um caminho potencial para a democratização do ensino. (p. 31)
}

Para próximas pesquisas, percebe-se necessária a investigação sobre as críticas às tentativas de implementação da Escola Primária Integral, aos projetos voltados para a educação popular e, atualmente, aos ciclos. Sobre estes, sabe-se que, embora as pesquisas sobre desempenho não tenham apontado pior ou menor aprendizagem entre alunos que estão matriculados nessa modalidade de organização escolar (Barretto, 2008; Franco, 2001), a crítica ao projeto inclui, com muita frequência, a interpretação de que essas escolas não têm ensinado o suficiente e de que isso seria resultado da não-reprovação. 


\section{Conclusão}

Este estudo partiu da necessidade de abordar a implementação dos ciclos como debate que se dá situado entre as relações de sociedade e escola, relações que se refletem na escola por meio de sua cultura escolar. Trazendo a crítica à escola seriada, buscou-se compreender em qual entendimento se assentam as práticas em relação a condutas, modos de vida, saberes escolares, saberes da experiência dos alunos, uso e distribuição do espaço, modos de pensar e ideias compartilhadas que compreendem a cultura escolar. Para isso, contextualizou-se a implementação dos ciclos de formação na rede municipal de Porto Alegre.

A crítica ao modelo de organização escolar seriada tem sido realizada com base em vários argumentos:

a) se todos os seres humanos aprendem por toda a vida, seria impossível alegar que algumas crianças não aprendem na escola, responsabilizando-as por esse não-aprender, como fazem as práticas de reprovação do aluno nas escolas;

b) o tempo escolar seriado é um tempo fragmentado e hierarquizado, organizado sobre uma lógica excludente (Arroyo, 2007);

c) a orientação homogeneizadora da escola confirma e legitima as diferenças sociais, transformando-as em diferenças de caráter individual (Gimeno Sacristán, 1998).

$\mathrm{Na}$ medida em que afirma a existência de um tempo máximo possível para que a aprendizagem pretendida aconteça (um ano letivo, em geral), a escola seriada nega a capacidade de aprender de alguns seres humanos, ou, em melhor hipótese, responsabiliza individualmente aqueles que não aprenderam o previsto dentro do tempo estipulado. Ao final do período que a escola ofereceu para o sujeito aprender, a avaliação classificatória define aqueles que podem seguir com sua turma escolar e os que não podem porque não aprenderam e, portanto, são menos capazes.

Os desafios apresentam-se ligados à necessidade de modificar a cultura escolar, suas práticas e processos, em busca de modelos escolares mais próximos das necessidades dos estudantes. Isso tem gerado algumas das propostas alternativas que podem representar um movimento significativo de tentativa de mudança.

Entre as propostas trazidas neste estudo - Educação Primária Integral, educação popular e organização escolar em ciclos - foram identificados alguns pontos que podem contribuir com o entendimento das transformações almejadas. Embora as mudanças propostas nesses três movimentos tenham semelhanças ao romper com o modelo educacional hegemônico vigente, apresentam diferenças na radicalidade em que são propostas essas mudanças.

O caráter radical da educação popular e da organização em ciclos de formação aqui trazidos prima por trabalhar o conhecimento de forma contextualizada e crítica, esforçando-se para identificar, nas realidades regionais, problemas capazes de desencadear estudos voltados para a transformação social. Ao mesmo tempo, propõe reconhecer os saberes presentes nos grupos de trabalho como ponto de partida para a construção de outros conhecimentos.

Ao estudar o processo de organização escolar em ciclos de formação, em Porto Alegre, foi possível observar que algumas práticas docentes parecem contribuir mais para a escola no atendimento das diversidades com as quais ela trabalha:

a) planejamento coletivo e interdisciplinar entre os anos escolares; isto é, o currículo é pensado como desenvolvimento conceitual, de forma dialogada entre as disciplinas escolares e para um conjunto de anos escolares, considerando as possibilidades de desenvolvimento dos alunos na faixa etária atendida;

b) organização dos tempos escolares de forma contínua, com a concentração dos tempos em áreas/disciplinas específicas, e não sua fragmentação durante a semana de aula;

c) oportunidade de espaços de aprendizagem diferenciados para dar conta das necessidades de aprendizagem específicas dos alunos: 
salas de apoio, laboratórios de aprendizagem, atendimento por professores de apoio, sala de recursos e outros;

d) incentivo, na organização das aulas, às trocas de experiências entre alunos com saberes diferentes;

e) práticas avaliativas baseadas no diálogo, coletivas e direcionadas para o conjunto da escola, tendo como foco a melhoria do que se faz, sem a perspectiva de exclusão (reprovação ou penalização de alunos por meio de notas baixas) (Fetzner, 2007).

A transformação realizada pela escola organizada em ciclos quando compartilha a construção curricular entre professores, famílias, estudantes (em uma perspectiva crítica) constroi outras regras e autoriza outros conhecimentos. Esses fazeres parecem fundamentais para uma escola que se quer democrática.

\section{Referências bibliográficas}

ARROYO, Miguel. Imagens quebradas: trajetórias e tempos de alunos e mestres. 2. ed. Petrópolis: Vozes, 2007.

AZEVEDO, José C. A democratização da escola no contexto da democratização do Estado: a experiência de Porto Alegre. In: SILVA, Luiz Heron. Escola cidadã: teoria e prática. Petrópolis: Vozes, 1999. p. 12-30.

Escola cidadã: desafios, diálogos e travessias. Petrópolis: Vozes, 2000.

. Reconversão cultural da escola: mercoescola e escola cidadã. Porto Alegre: Sulina/Editora Universitária Metodista, 2007. BAHIA. Lei $n^{\circ} 1.846$, proposta por Anísio Teixeira e aprovada em 14 de agosto de 1925 para reformar a Instrução Pública do Estado da Bahia. Bahia, 1925.

BARRETTO, Elba S. As escolas em ciclos e seus resultados no processo ensino-aprendizagem. In: FETZNER, Andréa R. Ciclos em revista: avaliação - desejos, vozes, diálogos e processos. v. 4. Rio de Janeiro: Wak, 2008. p. 195-212.

BARRETTO, Elba S.; MITRULIS, Eleny. Trajetória e desafios dos ciclos escolares no Brasil. In: PERRENOUD, Philippe. Os ciclos de aprendizagem: um caminho para combater o fracasso escolar.
Trad. Patrícia Chittoni Ramos Reuillard. Porto Alegre: Artmed, 2004. p. 189-226.

BARRETTO, Elba S.; SOUSA, Sandra Zákia. Estudos sobre ciclos e progressão escolar no Brasil: uma revisão. Educação \& Pesquisa, v. 30, n. 1, p. 31-50, 2004.

BRASIL. INSTITUTO BRASILEIRO DE GEOGRAFIA E ESTATÍSTICA. Produto interno bruto dos municípios 20032006. 2008a. Disponível em: <http://www.ibge.gov.br/home/ estatistica/economia/pibmunicipios/2006/tab01.pdf>. Acesso em: 14 nov. 2008.

MINISTÉRIO DA EDUCAÇÃO. INSTITUTO NACIONAL DE ESTUDOS E PESQUISAS EDUCACIONAIS ANÍSIO TEIXEIRA. Censos escolares 2005 e 2006. 2008b. Disponível em: <http://www.inep.gov.br/basica/censo/Escolar/Sinopse/ sinopse.asp>. Acesso em: 14 nov. 2008.

. CONSELHO NACIONAL DE EDUCAÇÃO. Parâmetros Curriculares Nacionais. Documento Introdutório. 2005a. Disponível em: <http://portal.mec.gov.br/seb/arquivos/pdf/livro01. pdf >. Acesso em: 14 nov. 2005.

. MINISTÉRIO DO TRABALHO E EMPREGO. Rais: estatísticas. 2005b. Disponível em: <http://www.ibge.gov.br/home/ estatistica/economia/municípios>. Acesso em: 15 jan. 2005.

CASSEN, Bernard. Democracia participativa em Porto Alegre: uma experiência exemplar no Brasil. Jornal de olho no orçamento, Porto Alegre: Cidade, p. 4, set. 1998.

CAVALIÉRI, Ana Maria V. Escola de educação integral: em direção a uma educação escolar multidimensional. 1996. 193 f. Tese (Doutorado em Educação) - Faculdade de Educação, Universidade Federal do Rio de Janeiro, Rio de Janeiro, 1996.

DURAN, David. Utilizar pedagogicamente as diferenças entre alunos: uma prática de tutoria entre iguais. In: FETZNER, Andréa Rosana (Org.). Ciclos em revista: a aprendizagem em diálogo com as diferenças. v. 3. Rio de Janeiro: Wak, 2008. p. 13-32.

FETZNER, Andréa R. Entre a regulação e a transformação: a experiência com complexos temáticos na organização do ensino em Porto Alegre (1995/2004). In: CONGRESSO LUSO-BRASILEIRO SOBRE QUESTÕES CURRICULARES, 4., Florianópolis, 2008. Anais... Florianópolis: UFSC, 2008. 1 CD-ROM.

. Falas docentes sobre a não-aprendizagem escolar nos ciclos. 2007. 167 f. Tese (Doutorado em Educação) - Faculdade de Educação, Universidade Federal do Rio Grande do Sul, Porto Alegre, 2007. 
FRANCO, Creso (Org.). Avaliação, ciclos e promoção na avaliação. Porto Alegre: Artmed, 2001.

FREIRE, Paulo. Pedagogia do oprimido. Porto: Afrontamento, Ed. João Barrote, 1975.

GANDIN, Luís Armando. Criando alternativas reais às políticas neoliberais em educação: o projeto Escola Cidadã. In: APPLE, Michael W.; BURAS, Kristen L. (Orgs.). Currículo, poder e lutas educacionais: com a palavra os subalternos. Trad. Ronaldo Cataldo Costa. Porto Alegre: Artmed, 2008. p. 221-243.

GERMANO, José Willington. Lendo e aprendendo: a Campanha de Pé no Chão. São Paulo: Autores Associados/Cortez, 1982.

GHANEM, Elie. Educação escolar e democracia no Brasil. Belo Horizonte: Autêntica/Ação Educativa, 2004.

GIMENO SACRISTÁN, José. O currículo: os conteúdos do ensino ou uma análise da prática? In: GIMENO SACRISTÁN, José; PÉREZ GOMÉZ, Angel Ignácio (Orgs.). Compreender e transformar o ensino. Trad. Ernani F. da Fonseca Rosa. 4. ed. Porto Alegre: Artmed, 1998. p. 119-148.

KRUG, Andréa. Ciclos de formação: uma proposta transformadora. 2. ed. Porto Alegre: Mediação, 2001.

LÖWY, Michel (Org.) O marxismo na América Latina: uma antologia de 1909 aos dias atuais. Trad. Cláudia Schilling e Luiz Carlos Borges. São Paulo: Fundação Perseu Ábramo, 1999.

MAINARDES, Jefferson. Reinterpretando os ciclos de aprendizagem. São Paulo: Cortez, 2007.

MOREIRA, Antonio Flávio B. Currículos e programas no Brasil. 14. ed. Campinas: Papirus, 2007.

NAVARRO, Zander. Uma análise do OP: sua implantação e desenvolvimento. In: GENRO, Tarso. Porto da cidadania. Porto Alegre: Artes e Ofícios, 1997. p. 10-23.

PARO, Vitor Henrique. Escritos sobre educação. São Paulo: Xamã, 2001.

PILLA VARES, Sônia et al. Estado, democracia e educação: construindo a qualidade social. Porto Alegre: SMED, 1996. Mimeografado.

POCHMANN, Marcio. O país dos desiguais. Le Monde Diplomatique Brasil, ano 1, n. 3, p. 16-18, out. 2007.
ROCHA, Silvio (Org.). Proposta político-educacional para a organização dos espaços-tempos na escola municipal. Cadernos Pedagógicos, Porto Alegre: SMED, n. 9, dez. 1996.

SMED - SECRETARIA MUNICIPAL DE EDUCAÇÃO DE PORTO ALEGRE. II Congresso Municipal de Educação: teses e diretrizes. Cadernos Pedagógicos, n. 21, Porto Alegre: SMED, mar. 2000.

VIEIRA, Sofia Lersche; FREITAS, Isabel Maria Sabino. Política educacional no Brasil: introdução histórica. Brasília: Plano, 2003. VIÑAO FRAGO, Antonio. História de la educación e história cultural: posibilidades, problemas, cuestiones. Revista Brasileira de Educação, ANPEd, n. 0, p. 63-79, set./dez. 1995.

VYGOTSKY, Lev S. Obras escogidas: psicología infantil. Tomo IV. Madrid: Visor, 1996.

WEREBE, Maria José; NADEL-BRULFERT, Jaqueline. Henri Wallon: psicologia. Trad. Elvira Lima. Coordenação Florestan Fernandes. São Paulo: Ática, 1986. (Coleção Grandes Cientistas Sociais, 52.)

ANDRÉA ROSANA FETZNER (KRUG), doutora em educação pela Universidade Federal do Rio Grande do Sul (UFRGS), é professora visitante pelo Programa de Apoio a Projetos Institucionais com a Participação de Recém-Doutores (PRODOC, Coordenação de Aperfeiçoamento de Pessoal de Nível Superior CAPES) no Programa de Pós-Graduação em Educação, Cultura e Comunicação da Universidade do Estado do Rio de Janeiro (UERJ), na Faculdade de Educação da Baixada Fluminense. Publicações recentes: é organizadora da publicação Ciclos em revista (Rio de Janeiro: Wak, 2007-2008); Ciclos de formação: uma proposta transformadora (3. ed. Porto Alegre: Mediação, 2006). Pesquisa atual: "Os ciclos e seus impactos na produção de novas práticas escolares", com financiamento da CAPES e da Fundação de Amparo à Pesquisa do Estado do Rio de Janeiro (FAPERJ). E-mail: akrug@uol.com.br

Recebido em outubro de 2008 Aprovado em janeiro de 2009 